\title{
NEGOCIAÇÃO DE IDENTIDADES EM UNIVERSIDADE PÚBLICA PARANAENSE: ACADÊMICOS DESCENDENTES DE POLONESES
}

\author{
Negotiation of Identities in a Public University in Parana: College Students \\ of Polish Descendants
}

\author{
Bernardete RYBA \\ Universidade Estadual do Paraná/UNESPAR - Campus de União da Vitória \\ bernardeteryba@gmail.com \\ https://orcid.org/0000-0001-7725-8884
}

RESUMO: Este artigo tem por base minha pesquisa de doutorado (UFPR, 2019). O estudo é pautado em perspectiva de investigação qualitativa, com enfoque interpretativo e traz à discussão negociações sobre aspectos culturais e identitários promovidas por acadêmicos descendentes de poloneses que estudam em uma universidade pública estadual paranaense (Universidade Estadual do Paraná/UNESPAR Campus de União da Vitória). Neste artigo, abordamos a negociação de identidades em relação ao uso da língua polonesa e da língua portuguesa nos ambientes universitário e familiar. Para esse propósito, utilizamo-nos de narrativas curtas e escritas. $\mathrm{O}$ embasamento teórico está respaldado em Bhabha (2014), Blommaert (2013), Canclini (2015), Cuche (1999), Georgakopoulou (2014), Hall (2006, 2009), Moita Lopes (2002, 2013), Pavlenko; Blackledge (2004), Silva (2009), Wachowicz (1970), entre outros. Resultados apontam que, neste corpus, o uso da língua polonesa restringe-se ao ambiente familiar. PALAVRAS-CHAVE: Negociação de identidades; Descendentes de poloneses no Paraná; Acadêmicos descendentes de poloneses.

\begin{abstract}
This article is based on my doctoral research (UFPR, 2019). The study is based on a qualitative research perspective, with an interpretative focus and brings to the discussion negotiations on cultural and identity aspects promoted by college students of Polish descents, who study at a state public university in Parana (Universidade Estadual do Paraná/UNESPAR - Campus de União da Vitória). In this article, we approach the negotiation of identities in relation to the use of the Polish and the Portuguese languages in college and family environments. For that purpose, we use short written narratives. The theoretical basis is supported by Bhabha (2014), Blommaert (2013), Canclini (2015), Cuche (1999), Georgakopoulou (2014), Hall (2006, 2009), Moita Lopes (2002, 2013), Pavlenko; Blackledge (2004), Silva (2009),
\end{abstract}


Wachowicz (1970), among others. Results indicate that, for this corpus, the use of the Polish language is restricted to the family environment. KEYWORDS: Identity Negotiations; Polish descents in Parana; College students of Polish descents.

\section{CONSIDERAÇÕES INICIAIS}

$\mathrm{O}$ interesse pelo tema abordado neste artigo surgiu tendo em vista o grande contingente de descendentes de poloneses presentes nos cursos ofertados pela Universidade Estadual do Paraná (UNESPAR) - Campus de União da Vitória, na qual sou docente no Curso de Letras. Grande parte dos imigrantes poloneses vieram ao Brasil e ao Paraná para suprir a mão de obra agrícola, após a libertação dos escravos; muitos dos seus descendentes são agricultores e, entre os filhos desses agricultores, estão alguns de nossos acadêmicos.

Neste artigo são apontados, através de excertos de narrativas autobiográficas escritas em língua portuguesa ("ferramenta de pesquisa"), por alguns desses acadêmicos, considerações e posicionamentos sobre suas identidades polono-brasileiras (negociação de identidades), principalmente (neste artigo), em relação ao uso (ou não) da língua polonesa nos ambientes aos quais eles pertencem. Temos, neste momento e neste espaço, um "recorte" de minha pesquisa de doutorado (tese) apresentada na UFPR, na PósGraduação em Letras/Estudos Linguísticos, em 2019, na qual são discutidos outros fatores importantes para a formação das identidades, tais como: crenças religiosas; participação em eventos de tradição polonesa; sentimentos pelos antepassados, entre outros.

A metodologia empregada levou em conta princípios básicos da etnografia: registro de dados obtidos; interpretação e reflexão desses dados, caracterizando, dessa forma, a pesquisa, como um estudo qualitativo-interpretativo, pois, entendemos que a realidade não pode ser dissociada de nosso conhecimento sobre ela e se dá em momentos e contextos específicos.

Os sujeitos pesquisados foram "selecionados", seguindo dois critérios: ser descendente de poloneses e estar cursando alguma graduação na UNESPAR - Campus de União da Vitória. As narrativas foram produzidas na instituição, em local previamente designado para garantir o sigilo dos dados. Todo o material colhido foi submetido ao Conselho de Ética e foram retiradas quaisquer "marcas" que pudessem identificar os sujeitos. A eles, foram atribuídos nomes fictícios; foram assinados Termos de Consentimento para o uso dos dados nesta pesquisa.

Estruturamos este artigo, no tocante à parte teórica, em: CULTURAS DOS 
IMIGRANTES, em que desmistificamos a imagem de que a cultura é imutável, estagnada e transportada do país de origem para o país que acolhe os imigrantes. A cultura é uma construção social que se faz, refaz e modifica continuamente, sofrendo influências diversas; não é um produto acabado, está sempre em transformação e adaptação. Usamos para a discussão: Canclini (2015) e Cuche (1999). Em seguida, em CULTURAS E IDENTIDADES, abordamos: a questão de que os sujeitos assumem diferentes identidades em momentos diferentes e que elas (as identidades) são constituídas na e pela linguagem, vinculadas às relações de poder; o papel social do Estado e noções sobre identidades sincréticas, estratégias e deslocamentos de identidades. O respaldo teórico está em Bhabha (2014), Hall (2006, 2009), Moita Lopes (2002), Pavlenko; Blackledge (2004), entre outros. Em NARRATIVAS DE IDENTIDADES COMO FERRAMENTA DE PESQUISA, enfatizamos a importância das narrativas para elucidar questões abordadas em negociação de identidades, pois trazem informações do passado e do presente, bem como as expectativas para o futuro. Os teóricos usados são: Georgakopoulou (2014) e Pavlenko; Blackledge (2004).

Na ANÁLISE E DISCUSSÃO DE DADOS, utilizamos excertos de narrativas produzidas por acadêmicos descendentes de poloneses. Blommaert (2013), Canagarajah (2004), Georgakopoulou (2014) e Pavlenko; Blackledge (2004), entre outros, contribuem para as análises. As CONSIDERAÇÕES FINAIS apontam que o uso da língua polonesa, para esse corpus, acontece nos ambientes em que os avós (imigrantes ou descendentes de poloneses) fazem parte ou convivem com as famílias dos acadêmicos pesquisados e, principalmente, nas famílias nas quais os pais moram no interior e/ou são agricultores. Nesta pesquisa, os fatos que propiciaram o uso menor da língua polonesa foram a entrada para a escola e para a vida laboral.

\section{CULTURAS DOS IMIGRANTES}

O vocábulo "cultura" vem sendo usado em diversos campos de pesquisa, transcendendo seu significado. Vemos seu uso crescer continuamente, principalmente nas áreas político-governamentais e nas empresas - o sentido polissêmico da palavra lhe permite inúmeros significados e particularizações: uma delas é a "cultura dos imigrantes", termo utilizado inicialmente na França, nos anos 70 (CUCHE, 1999, p. 225). Na França, a essa época, os imigrantes eram considerados "trabalhadores estrangeiros" que vinham para suprir determinadas mãos de obra e as preocupações sobre essa imigração giravam em torno de trabalho, adaptação ao trabalho, condições de trabalho, etc. Em 1974, 
"descobre-se o aspecto durável da imigração" (CUCHE, 1999, p. 225) - apesar da crise de emprego, os imigrantes não voltaram aos países originários e trouxeram suas famílias para o território francês.

A preocupação do então governo, presidente Giscard d'Estaing, passou para a esfera das práticas cotidianas das populações imigrantes. Foi criada uma agência nacional e um documento: "A Nova Política da Imigração", que incentivava os imigrantes a praticar a sua cultura de origem, ao mesmo tempo que descobriam aspectos novos da cultura francesa; mostrava também as culturas dos países dos imigrantes aos franceses. Para Cuche (1999, p. 226-227), essa promoção/incentivo da cultura dos imigrantes visava o seu regresso à terra natal, mas coincidiu com o surgimento de movimentos regionalistas (bretão, corso, etc.) que denunciavam o centralismo cultural da França e reivindicavam o reconhecimento da pluralidade cultural ao defender as minorias culturais existentes na França.

O termo "cultura dos imigrantes" faz menção à "cultura de origem" dos imigrantes, como se a sua identidade fosse imutável, não fosse construída socialmente, como se fosse um caráter genético ao qual não se pode fugir. Traz também a noção de que a "cultura de origem" (aqui confundida com cultura nacional) fosse homogênea, como se cada grupo emigrado de um país não possuísse especificidades e como se ela permanecesse estagnada (como era em sua origem) no país de acolhida, não fosse modificada por situações políticoeconômicas. Há, portanto, uma falsa imagem de que a homogeneidade e a imutabilidade estão presentes nos grupos imigrados e no país de origem, como se a construção social não fosse um processo que se faz e se modifica continuamente.

Portanto, a "cultura dos imigrantes" é definida em função de critérios e interesses no caso específico da França da década de 70, seria a representação social do "diferente", do "estranho" (estrangeiro). Para Cuche (1999, p. 230), a "cultura dos imigrantes" é "definida a partir de toda uma série de sinais exteriores (práticas alimentares, religiosas, sociais, etc.) cujo significado profundo ou coerência não são compreendidos, mas que permitem situar o imigrante enquanto imigrante, lembrar suas origens [...]". Muitas vezes (e foi o caso da França na época mencionada), são destacados aspectos culturais ligados à esfera do lazer dos imigrantes - as "associações culturais" são locais onde, via de regra, pratica-se a língua materna; artes tradicionais como música, canto, danças; a cozinha tradicional - entretanto, nas esferas sociais de trabalho, escolar, etc., os imigrantes são chamados a "descobrir"/fazer parte da cultura do país que os recebe.

As "culturas dos imigrantes" são, muitas vezes, depreciadas, dominadas, e a cultura de origem que alguns grupos de imigrantes tentam preservar são apenas "culturas 
em migalhas", cultura fragmentária, reduzida a alguns elementos descontextualizados que não mais formam um sistema (CUCHE, 1999, p. 231) e que servem para, no grupo de imigrantes, "provar" fidelidade à comunidade de origem e reconhecimento pelos seus pares. Cuche (1999, p. 232) afirma que:

Os imigrantes fazem uma resistência cultural na medida de suas possibilidades. No entanto, queiram ou não, seu sistema cultural evolui. Mesmo quando eles se consideram totalmente fiéis à sua tradição, mudanças são produzidas nas suas referências culturais. É impossível que eles se mantenham completamente impermeáveis à influência cultural da sociedade que os cerca. Quanto mais longa for sua estada nesta sociedade, mais decisiva será a sua influência. As culturas dos imigrantes não podem então ser confundidas de maneira redutora com suas culturas de origem. São culturas vivas e dinâmicas que animam os grupos de imigrantes, compostos de várias gerações [...]. Tomadas globalmente como sistemas, as culturas dos imigrantes não param de evoluir, mesmo que certos elementos particulares possam ser conservados em um estado quase inalterado.

Concordando com a colocação citada acima, Canclini (2015, p. XXVI) alerta que o sujeito que migra nem sempre "está especialmente disposto a sintetizar as diferentes estâncias de seu itinerário, embora - como é claro - lhe seja impossível mantê-las encapsuladas e sem comunicação entre si”, pois não há fronteiras de quaisquer espécies entre as culturas. Portanto, a expressão "culturas dos imigrantes", embora passe "uma imagem" de situação estática em relação às culturas pré-existentes localmente, deve trazer subliminarmente a mensagem de que as culturas sofrem influências diversas em tempo real e em função de situações em que ocorrem, que não são "produtos" acabados, que sempre estão em processos de transformações e adaptações.

Cada imigração congrega uma série de variáveis em sua forma de imigrar e de se estabelecer; os estudos precisam levar em consideração a estrutura social e familiar, se a imigração foi parte de um projeto imigratório governamental (como no Brasil, após a abolição da escravatura), como se deu a fixação dos imigrantes no país que os recebeu, para entender melhor como se processou a sincretização de sua cultura original com a cultura existente na nova localização - esse olhar auxilia a considerar a complexidade das diferenças culturais dos imigrantes em um país e a lembrar que "não há cultura que não tenha significação para aqueles que nela se reconhecem" (CUCHE, 1999, p. 239). Além disso, é preciso considerar que há diversidade de cultura em um grupo de imigrantes, o que torna essa hibridação mais complexa ainda. 
Lembramos, por oportuno, que, embora o vocábulo "cultura" represente, em sentido amplo, um complexo de comportamentos e atitudes aprendidos, desenvolvidos e repassados de uma geração a outra ao longo dos tempos (pelos sujeitos), também, em sentido mais restrito, representa os comportamentos e atitudes aprendidos, desenvolvidos e repassados de uma geração a outra por uma comunidade/sociedade em um determinado espaço de tempo - a língua é inerente a todos esses processos (CUCHE, 1999). Essa é a compreensão de cultura que assumimos neste artigo.

\title{
CULTURAS E IDENTIDADES
}

Atualmente, muito se discute, em nossa sociedade, as identidades que formam os sujeitos pós-modernos e a crise dessas identidades em construção/transformação. Segundo Bhabha (2014), na pós-modernidade, o ser humano se encontra em constantes atos de se reconstruir e de se reinventar, atos esses que propiciam as (re)construções de suas culturas e identidades. Para Hall (2009, p. 38), identidade é um processo de constantes transformações:

\begin{abstract}
Assim, a identidade é realmente algo formado ao longo do tempo, através de processos inconscientes, e não algo inato, existente na consciência no momento do nascimento. Existe sempre algo "imaginário" ou fantasiado sobre sua unidade. Ela permanece sempre incompleta, está sempre "em processo", sempre "sendo formada".
\end{abstract}

A importância de estudos sobre construção/reconstrução de identidades ganhou impulso recentemente, pois diz respeito ao ser humano que, no mundo pós-moderno, póscolonial e globalizado, encontra-se em dispersão, fragmentação e em constantes processos diaspóricos. Segundo Bhabha (2014, p. 331), "vivemos uma autoconstrução" (termo usado por Bhabha para nomear os atos constantes de que o ser humano, na modernidade, faz uso na construção e (re)invenção do seu "eu" - seu sujeito, seu tempo e sua cultura são permanentemente (re)construídos e (re)inventados). Hall (2009, p. 44) concorda com essa ideia:

As identidades, concebidas como estabelecidas e estáveis estão naufragando nos rochedos de uma diferenciação que prolifera. Por todo o globo, os processos das chamadas migrações livres e forçadas estão mudando de composição, diversificando as culturas e pluralizando as identidades culturais $[\ldots]$ 
Em relação à fragmentação a que está exposto o ser humano atualmente, Hall (2006, p. 13) afirma que:

$\mathrm{O}$ sujeito assume identidades diferentes em diferentes momentos, identidades que não são unificadas ao redor de um "eu" coerente. Dentro de nós há identidades contraditórias, entornando em diferentes direções de tal modo que nossas identificações estão sendo continuamente deslocadas.

O ser humano é, pois, não uno em sua identidade, mas pertencente a várias identidades - um misto do que era em momentos anteriores e do que é e/ou do que precisa ser agora. Como as pessoas circulam, emitem muitos discursos e negociam identidades múltiplas, dependendo da situação e dos interlocutores, algumas identidades podem ser destacadas e outras não.

Quando uma pessoa define a sua nacionalidade (brasileira, polonesa, ...), está utilizando uma expressão metafórica, pois a identidade não está ligada à genética. Para Hall (2006, p. 61), "nação não é apenas uma entidade política, mas algo que produz sentidos - um sistema de representação cultural" - sendo a escolha de nossas identidades determinada pelas "práticas discursivas impregnadas pelo poder" (MOITA LOPES, 2002, p. 37) e que levam em consideração diversos aspectos (gênero, raça, classe social, sexualidade, idade, etc.) que coexistem nas pessoas. Dessa forma, pessoas são diferentes em diferentes momentos e lugares.

Silva (2009, p. 76) aponta que identidade e diferença são constituídas na e pela linguagem e que estão vinculadas às relações de poder, portanto "a identidade e a diferença não são, nunca, inocentes”. Buchman (1995, p. 29) faz menção à relação de dominação imposta aos poloneses antes de imigrarem para o Brasil, quando a Polônia, invadida por outros países (Prússia, Áustria e Rússia e, mais tarde, Alemanha), sofreu a desagregação de suas terras e seu povo foi impedido de usar sua língua:

O processo de dominação de um povo sobre outro, além da dominação concreta - a política e a econômica - destrói também seu mundo simbólico [...]. Destruir seu mundo simbólico significa quase sempre a destruição de suas instituições e/ou o esmagamento da língua materna, o que quer dizer, o aniquilamento profundo da sua identidade cultural.

Com relação ao "aniquilamento" da identidade cultural e ao "esmagamento da língua materna”, lembramos Coracini (2003, p. 13), que, com respeito à crise de identidade 
que muitos estudiosos acreditam estarmos vivendo, informa-nos que essa crise é provocada pela "ideologia da globalização que pretende a homogeneização de tudo e de todos" e que "como que por efeito de resistência, as línguas minoritárias ou os dialetos em vias de desaparecimento, os grupos marginalizados se rebelam, acirrando as diferenças, lutando por sua sobrevivência e por um espaço na sociedade". Para Hall (2009), as minorias não ficam restritas aos seus "guetos": procuram extrapolar seus "enclaves" (segundo a Geografia Política: território com distinções políticas, sociais e/ou culturais que ficam inteiramente dentro dos limites de outro território). Lembramos aqui que, ao chegarem ao Brasil, muitos dos imigrantes formaram colônias (poloneses, inclusive) - os "guetos" de Hall (2009) - mas não ficaram restritos a elas (colônias) por vários motivos - vender os produtos de suas lavouras (no caso dos imigrantes poloneses) foi um deles.

Há, em comunidades bi/multilíngues, alternância de identidades - uma forma de não impor uma única identidade ou de omitir-se diante do outro; de tentar "negociar a diferença" (PAVLENKO; BLACKLEDGE, 2004). Esse fato é bem marcante na alternância das línguas usadas nas comunidades objeto de estudo: uso da língua polonesa com as pessoas com as quais há maior intimidade (familiares, por exemplo); uso de língua portuguesa/brasileira quando se dirigem a outras pessoas e/ou em locais onde imperam a formalidade. Portanto, as pessoas são sujeitos de muitos discursos apropriados a cada circunstância, e, esses discursos representam as nossas identidades. E qual é a língua que esses sujeitos falam? Polonesa, portuguesa, brasileira? Como os descendentes de imigrantes (poloneses, em nosso caso) se constituíram em relação às identidades e às línguas presentes em seus espaços?

Bourdieu, destacado sociólogo e pensador do século $\mathrm{XX}$, em seu ensaio "A identidade e a representação (1980, apud CUCHE, 1999, p. 186), orienta que só os grupos de detêm autoridade conferida pelo poder conseguem impor suas condições (autoridade legítima) de se fazer reconhecer como categoria representativa da realidade social e fazer valer seus próprios princípios. Cuche (1999, p.186) exemplifica essa situação ao citar o grupo dominante WASP (White Anglo-Saxon Protestant) nos Estados Unidos que classifica os outros americanos em duas categorias: grupos étnicos (compostos pelos descendentes de imigrantes europeus que não WASP) e grupos raciais (americanos "de cor", tais como negros, chineses, japoneses, porto-riquenhos, mexicanos). Os pertencentes ao grupo WASP se apresentam como isentos de qualquer categorização.

O poder de classificar leva à "etnicização" dos grupos subalternos. Os sujeitos identificados como portadores de características culturais exteriores podem ser marginalizados, transformados em minoria; muitas vezes, não há reconhecimento de 
especificidades culturais. A afirmação da "única identidade legitima" é apregoada pelo grupo dominante.

O Estado exerce um papel social que perpassa a identidade. Com a edificação dos Estados-Nações modernos, o Estado procura gerenciar a identidade, instaurando regulamentos e controles e, segundo Cuche (1999, p. 188), usando de meios como o reconhecimento de apenas uma identidade cultural para definir a identidade nacional, como aconteceu no período de afirmação da identidade brasileira, que ficou conhecido como Era Vargas (1930 à 1945). Esse período, no Brasil, ficou marcado pela política nacionalista que fechou escolas de imigrantes e os obrigou a usar a língua portuguesa. Essas ações do Estado provocaram revolta por parte dos grupos minoritários cujas identidades foram negadas e desvalorizadas, através de movimentos e reivindicações legais, como se pode observar (hoje) pelas políticas linguísticas de co-oficialização de línguas de imigrantes. Em algumas ocasiões, o sentimento de injustiça sofrido por um grupo minoritário provoca em seus membros um sentimento forte de vinculação à coletividade.

\begin{abstract}
Quanto maior for a necessidade da solidariedade de todos na luta pelo reconhecimento, maior será a identificação com a coletividade. O risco é, no entanto, de sair de uma identidade negada ou desacreditada para cair, por sua vez, em uma identidade que seria exclusiva, análoga à identidade dos que pertencem ao grupo dominante, e na qual todo indivíduo considerado como membro do grupo minoritário deveria se reconhecer, sob pena de ser tratado como traidor. Este fechamento em uma identidade cultural, que em certos casos apaga todas as outras identidades sociais de um indivíduo, será mutilante para ele, na medida em que ela leva à negação de sua individualidade (CUCHE, 1999, p. 191).
\end{abstract}

É preciso levar em conta que há heterogeneidade em todos os grupos sociais; que nenhum sujeito possui uma identidade unidimensional, pois a identidade é resultante da construção social e identidades mistas são frequentes na sociedade. Se tomarmos como exemplo jovens de origem imigrante, haverá "identidade mista" ou "dupla identidade". Para Cuche (1999, p. 193):

Ao contrário do que afirmam certas análises, estes jovens [de origem imigrante] não têm duas identidades opostas entre as quais eles se sentiriam divididos, o que explicaria sua perturbação de identidade e sua instabilidade psicológica e/ou social. Esta representação nitidamente desqualificante vem da incapacidade de pensar o misto cultural. Ela é explicada também pelo medo obsessivo de uma dupla lealdade que é veiculada pela ideologia nacional. Na realidade, como cada um faz 
a partir de suas diversas vinculações sociais (de sexo, de idade, de classe social, de grupo cultural ...), o indivíduo que faz parte de várias culturas fabrica sua própria identidade, fazendo uma síntese original a partir destes diferentes materiais. O resultado é, então, uma identidade sincrética e não dupla, se entendermos por isso uma adição de duas identidades para uma só pessoa. Como já foi dito, esta "fabricação" se faz somente em função de um contexto de relação específico a uma situação particular.

Canclini (2015, p. XXVI) diz que a oscilação entre a identidade de origem e a identidade de destino leva, às vezes, "o migrante a falar com espontaneidade a partir de vários lugares, sem misturá-los". Em outros casos, o sujeito aceita descentrar-se de sua história e desempenha vários papéis "incompatíveis e contraditórios de um modo não dialético: o lá e o cá que são também o ontem e o hoje, reforçam sua atitude enunciativa e podem trazer narrativas bifrontes", consideradas, por vezes, como "esquizofrênicas".

A noção de "dupla identidade", muitas das vezes, vem acompanhada de um caráter negativo, principalmente quando se refere a situações de imigração. Há, lembrando Cuche (1999, p. 193), inclusive discursos para "reabilitar" esses grupos. Se pensarmos na "identidade sincrética" mencionada anteriormente, a situação de dupla identidade não existe em seu estado "puro", pois cada indivíduo, dependendo da situação em que se encontra seu grupo, integra todas as identidades ligadas a sua história.

Cuche (1999, p.196) informa que "a identidade conhece variações, presta-se a reformulações e até a manipulações"; ela possui caráter dinâmico e flexível e é difícil de ser delimitada e também definida. Devido a sua dinamicidade e flexibilidade, que jamais atinge a situação de caráter definitivo, alguns autores, de acordo com Cuche (1999, p. 196), utilizam o conceito de "estratégia de identidade" - sob esse aspecto, a identidade é tomada como um meio para atingir um objetivo. $\mathrm{O}$ conceito de estratégia faz pensar que o indivíduo, sendo um ator social, utiliza alguns recursos de identidade de maneira estratégica. Podemos verificar isso nos movimentos de luta social que buscam revidar as relações de dominação.

Entretanto, se pensarmos a identidade como recurso de estratégia, precisamos levar em conta que os atores sociais, ao tentarem definir suas identidades, devem atentar para a situação social, para a relação de forças entre os grupos, para as manobras dos outros grupos. Muitas vezes, é preciso esconder a identidade para escapar à discriminação e, em casos extremos, para escapar ao massacre. Os judeus da Península Ibérica, no século $\mathrm{XV}$, converteram-se aparentemente ao catolicismo e secretamente mantinham-se fiéis a sua fé e ritos sagrados - a identidade judaica foi transmitida durante séculos dessa forma, 
até poder ser novamente assumida publicamente (CUCHE, 1999, p. 197).

Através do conceito de estratégia é que se explicam as chamadas "variações de identidades" ou "deslocamentos de identidades" - a relatividade dos fenômenos de identificação/identidade. Cada mudança social faz com que a identidade se desconstrua e se reconstrua, conforme a necessidade. A separação entre dois grupos etno-culturais não se dá exatamente por diferenças culturais, pois uma comunidade pode admitir pluralidades culturais. A separação ou "fronteira", termo utilizados por Barth (1969, apud CUCHE, 1999, p.200), "é a vontade de se diferenciar, através do uso de certos traços culturais, como marcadores de sua identidade específica". Pode acontecer que dois grupos que possuam inúmeros traços identitários muito semelhantes se considerem estranhos por se oporem por outros poucos traços culturais - é o caso de poloneses e ucranianos.

Cuche (1999, p.200) recorre ao conceito de "fronteira" de Barth para afirmar que "a etnicidade, que é o produto do processo de identificação, pode ser definida como a organização social da diferença cultural”. As relações sociais entre grupos étnicos diferentes não colaboram para que as diferenças culturais se tornem menores; são as situações sociais, econômicas e políticas que podem provocar deslocamentos de fronteiras identitárias. Para Cuche (1999, p. 202), a questão fundamental não é encontrarmos e/ou estudarmos as identidades particulares, mas procurarmos responder à questão: "Como, por que e por quem, em que momento e em que contexto é produzida, mantida ou questionada certa identidade particular?".

Pensarmos a língua, a partir da busca da identidade na diferença, segundo Scherer (2003, p. 121), é um “território profundo". Para a pesquisadora, "território é o intermédio do lugar de negociação que se faz com a língua, pela língua e na língua" (SCHERER, 2003, p. 121). Esse "território" (lugar de negociação) a que se refere a autora tem a sua base formada na história do sujeito e em como ele negocia o uso da língua nas diversas ocasiões que fazem parte da sua existência. Scherer (2003, p. 122) elucida que a língua não pré-existe

aos enunciados que a exprimem nem aos objetos simbólicos. Os dois são essenciais para que ela exista. De um lado, cada formação histórica é uma formação do simbólico e do enunciável; por outro lado, há a variação da formação, porque o simbólico mesmo muda/alterna/altera de modo, como, também os enunciados mudam/alternam/alteram de regime, de formas de dizer.

Como os sujeitos possuem formas diferentes de "ver" e "interpretar" tudo que os rodeia e os "objetos simbólicos" são de naturezas que diferem entre si, os sentidos 
atribuídos aos discursos produzidos pelos sujeitos serão diversos e, na negociação das identidades, serão produzidas as adequações aos discursos. Para Scherer (2003, p. 122), o "sujeito nada mais é do que o suporte e o efeito do seu discurso", pois ele (discurso), em sua formação, leva em conta muitas relações interiorizadas pelo sujeito, bem como aquelas que subjazem a ele - as conjunturas do tempo e do espaço em que são produzidas e levam em conta toda a formação adquirida pelo sujeito para essa produção (do discurso). Dessa forma, os discursos denotam as identidades presentes no sujeito, levando em conta seu tempo e seu espaço e o que se faz necessário para que haja entendimento.

\section{NARRATIVAS DE IDENTIDADES COMO FERRAMENTA DE PESQUISA}

As narrativas são elementos importantes para elucidar questões abordadas em negociação de identidades, segundo Georgakopoulou (2014). As migrações e as diásporas propiciaram, via de regra, tensões, fragmentações e deslocamentos de grupos/povos em busca de melhores condições para viver. As narrativas de identidades propiciam o conhecimento desses fenômenos, pois trazem sobre os sujeitos envolvidos as ligações entre passado, presente e expectativa de futuro. Entendemos que as narrativas são importantes e produtivas para compreender as negociações de identidades relacionadas aos processos migratórios, tais como a imigração polonesa ao Brasil.

Também são enriquecedoras porque possuem dimensão diacrônica e possibilitam que as identidades sejam apresentadas nessa dimensão. Lembramos Saussure (1995) e os conceitos de diacronia: ocorrências linguísticas que acontecem através do tempo e sincronia: ocorrências que acontecem ao mesmo tempo. As identidades não são somente opções discursivas, elas trazem informações do passado e do presente, segundo Hall (1990, apud PAVLENKO; BLACKLEDGE, 2004, p. 19). Uma história de vida nos traz uma visão dinâmica de identidade com o envolvimento de alguns indivíduos, posições de outros, revisões e criações de novas posturas de resistência ou de concordância, que procuram preservar algumas experiências e se lançar a novos desafios. As condições de produção das narrativas usadas neste artigo são diacrônicas, a "observação", o "olhar" é sincrônico.

Pavlenko; Blackledge (2004) embasam-se na "teoria do posicionamento" de Davies; Harré (1990) e Harré; van Langenhove (1999, apud PAVLENKO; BLACKLEDGE, 2004, p. 20) para analisar como as identidades são produzidas e negociadas. Essa teoria permite, segundo os autores, reunir as visões de identidades localizadas nos discursos e situações nas narrativas como observador e como sujeito. Pavlenko; Blackledge (2004, 
p.20) orientam que a teoria do posicionamento, ao trazer os pontos de vista presentes nas interações e nas narrativas, informam o posicionamento do outro, com a finalidade de o participante da pesquisa se posicionar; são repassados dois pontos de vista (dele e de seu “outro"). Negociação de identidades pode ser vista então como uma "interação" entre posicionamentos de indivíduos ou grupos.

É proposto por Pavlenko; Blackledge (2004, p.21), para a negociação de identidades, uma estrutura com classificação em três tipos: identidades impostas (que não são negociáveis em um determinado tempo e lugar); identidades assumidas (que são aceitas e não negociadas) e identidades negociadas (que são contestadas por grupos e indivíduos). Usamos essa proposição em nosso artigo.

Todos os tipos de identidades devem ser olhados como únicos, pois assim são as condições sócio-históricas nas quais elas ocorrem: identidades que não são passíveis de serem negociadas, em um contexto de tempo e lugar, podem ser negociadas se ocorrerem em outra circunstância (sócio-histórica) ou em outros tempos. Também há diferenças nos relatos/posicionamentos de um indivíduo para outro - algumas identidades podem ser questionadas por alguns, ao passo que para outros, esses mesmos itens não se apresentam de forma tão relevante. Pavlenko; Blackledge (2004, p.21) citam como exemplo as opções sexuais - prioridade nas negociações para alguns e não prioridade para outros. Lembramos que as prioridades não são definidas pelos indivíduos, mas pelas relações de poder da comunidade em que vivem.

As negociações de identidades para Pavlenko; Blackledge (2004, p.21) podem estar centradas em várias áreas, tais como: etnia e nacionalidade; gênero; raça; classe e status sociais; sexualidade; afiliação religiosa, mas também nas áreas de competência linguística e habilidade em segunda língua. As identidades são negociadas em lugares diversos como: família, grupos de interação, contextos educacionais, locais de trabalho, discursos públicos em políticas educacionais linguísticas e de imigração, entre outros.

\section{ANÁLISE E DISCUSSÃO DE DADOS}

Neste artigo, trazemos, a título de análise e discussão, excertos de relatos colhidos através de narrativas (escritas) de acadêmicos descendentes de poloneses, da Universidade Estadual do Paraná - UNESPAR, Campus de União da Vitória-PR. O recorte é parte do corpus formado por sujeitos participantes da pesquisa de minha tese defendida em 2019, na Universidade Federal do Paraná - UFPR, na área de Letras/Estudos Linguísticos. Para este artigo, foram utilizadas as informações de cinco acadêmicos, cujos nomes e 
informações pessoais foram preservados (utilizamos nomes fictícios), em observância às normas estabelecidas pelo Comitê de Ética. Também, aqui, são apresentados somente os trechos que se referem à negociação de identidades quanto ao uso da língua polonesa e da língua portuguesa, nos ambientes familiar e acadêmico. Os excertos estão reproduzidos tal e qual foram escritos e encontram-se entre aspas; em seguida está o nome fictício atribuído ao seu autor.

Por terem vindo da Polônia, tinham dificuldades com a Língua Portuguesa, assim o idioma predominante nas conversas, principalmente de família, era o polonês. - LUIZ.

O participante está se referindo ao avô paterno, que imigrou para o Brasil e aqui casou com sua avó, também descendente de poloneses; apresenta uma “justificativa" para o uso da língua polonesa em família - os avós possuíam pouco conhecimento da língua portuguesa.

[...] a qual falava conosco na maioria das vezes em polonês. - LUIZ.

A referência é para a avó paterna. Notamos a presença da língua polonesa; a localização da residência é uma comunidade onde também moram outros poloneses e seus descendentes.

Ela dizia que era importante que aprendêssemos polonês para não deixar a língua morrer. - LUIZ.

Ela é a avó paterna do participante LUIZ. Podemos notar, pelo excerto, uma situação que Pavlenko: Blackledge (2004) chamam de identidade imposta - a língua, sendo parte constituinte da identidade e da cultura, "precisava/era importante" que fosse aprendida e usada. Georgakopoulou (2014) lembra que as narrativas precisam ser contextualizadas e que o espaço social (local) permite certas escolhas de linguagem em detrimento de outras. A comunicação feita através da língua polonesa era comum na localidade/comunidade onde vivia a avó de LUIZ, pois muitos vizinhos e amigos possuíam a mesma descendência. Os pais de LUIZ (a mãe também é filha de poloneses) colaboravam para que a língua e as identidades polonesas estivessem presentes, mas alternavam com a presença da língua portuguesa. Podemos perceber essa situação em: 
Além de ouvir o polonês falado pelos pais em casa [...] pois os pais falavam muito o polonês, principalmente quando não queriam que os filhos soubessem o teor das conversas. - LUIZ

O acima relatado indica que se a conversa era passível de ser ouvida pelos filhos, era produzida em língua polonesa. Notamos a alternância de códigos; também há a indicação de que, embora os pais usassem a língua polonesa entre si, as crianças já possuíam dificuldades para entendê-la e/ou usá-la (pois os pais a usavam para "não revelar" o teor do assunto). Notamos a imposição de identidade linguística brasileira quando LUIZ conta que:

Quando fomos à escola, nas séries iniciais, sofremos um pouco, porque a professora exigia que tudo fosse falado em Português... - LUIZ.

A situação passa para a negociação de identidade, pois o participante, logo a seguir, narra que:

[...] e as vezes misturávamos as línguas, um pouco Português, um pouco Polonês [...] - LUIZ.

No seguimento da narração, acontece uma situação de identidade assumida:

[...] mas com o passar do tempo e muita leitura entendemos que devíamos falar e escrever em português - LUIZ.

O fato de "assumir" outra língua faz com que LUIZ vá "minimizando" sua primeira língua - não "apagando" totalmente, como podemos perceber no excerto declarado logo a seguir, mas a segunda língua é hoje seu principal meio de comunicação/discurso.

Atualmente, não tenho domínio completo sobre o idioma polonês, mas nas conversas de família consigo me defender - LUIZ.

Não podemos deixar de notar o uso de "consigo me defender" - entendemos que a mesma imposição de uso da língua que a avó fez quando ele era criança ("não deixar a língua morrer") é feita por parte da família (os mais velhos e os que moram em comunidades onde se usa a língua polonesa com maior frequência).

$\mathrm{Na}$ narrativa de JOSÉ, da mesma forma, o uso da língua polonesa foi facilitado pela família - avós e pais. Em seus relatos, há a presença da identidade assumida. 
Meus avós e meus pais sempre falavam o polonês em casa. A minha primeira língua foi o polonês, portanto é uma língua muito familiar para mim - JOSÉ.

Sempre pratiquei o polonês quando ia na casa dos avós ou na casa dos pais. Isto despertou o interesse em estudar mais a língua polonesa. Eu estudava o polonês em casa. Daí tive a oportunidade de fazer uma especialização na [retiramos o nome da instituição] e também cursos mais rápidos na Polônia - JOSÉ.

Faz-se presente também o desejo de se aprimorar na língua polonesa - e a identidade assumida fica mais evidente:

Isto [refere-se à especialização e aos cursos feitos na Polônia] me ajudou a melhorar muito o polonês e principalmente conhecer a sua gramática que é bastante difícil. Enquanto estudava o polonês, também iniciei aulas para alunos do colégio [suprimimos o nome do colégio para preservar o anonimato do participante] e comunidade, através do CELEM. Como não havia salas disponíveis no colégio, as aulas aconteciam no Salão Paroquial e mais tarde no antigo colégio das [apagamos o nome do estabelecimento]. Também ministrei aulas particulares com a [...] e o [retiramos o nome da escola e do centro educacional], sempre com o apoio do consulado polonês - JOSÉ.

Junto ao desejo de aprimorar-se no uso da língua polonesa, percebemos que o apoio do consulado polonês para que aulas desse idioma acontecessem junto à comunidade e, principalmente, junto à escola pública (que detinha à época o gerenciamento da escolha da língua a ser trabalhada no Centro de Língua Estrangeiras Modernas - CELEM do município), propiciava a JOSÉ o que Foucault (1972, apud CANAGARAJAH, 2004) afirma quando observa que, embora precisemos falar/reproduzir as vozes dos discursos presentes nas instituições e que esses atos devem ser em língua nacional, não precisamos reproduzi-las na íntegra; que, nos interstícios desses discursos, podemos nos posicionar, levando em consideração os nossos valores e interesses e deixar que nossas "vozes próprias" apareçam. Para Canagarajah (2004, p. 268) "sempre há espaço para negociar, modificar e reconfigurar - se não, resistir - discursos dominantes". Essa "voz" é a manifestação de um posicionamento no discurso, através da linguagem e, nesse caso, essa "construção retórica" é facilitada pelas "regras institucionais": o fato de ser professor de uma instituição pública estadual (CANAGARAJAH, 2004, p. 267). 
Na minha casa falamos polonês porque a minha avó paterna mora conosco - ela fala um pouco em português, um pouco em polonês. Está um pouco surda, então, às vezes, quando falamos em português, ela faz de conta que não está ouvindo (eu acho que é fingimento). Se começamos a falar em polonês, ela participa imediatamente da conversa - MARIA.

Na narrativa de MARIA, verificamos a presença de alternância do uso da língua polonesa e portuguesa propiciada pela presença da avó na rotina diária da família. Embora ela (avó paterna) use o português em algumas ocasiões, prefere se comunicar em sua língua materna. É levantada a hipótese (por MARIA) de que a avó "faz de conta" que não ouve bem quando a comunicação é feita em língua portuguesa.

Tomamos cuidado quando existe alguém que não entende o idioma estrangeiro e está em nossa casa ou participando de nossas conversas; achamos que é falta de educação - as pessoas podem interpretar como falta de educação - MARIA.

Fica claro que há, por parte de MARIA e sua família, um certo cuidado (não imposição de suas identidades) e negociação (de uso de línguas) em determinados locais, nos quais há presença de outras identidades, corroborando com Hall (2006, p. 13) que afirma que "o sujeito assume identidades diferentes em diferentes momentos". Pavlenko; Blackledge (2004) informam que, em ambientes multilíngues (é o caso de MARIA), as escolhas linguísticas e as posturas que os sujeitos assumem são inseparáveis das visões que os interlocutores possuem sobre suas identidades e as identidades dos outros. Posicionamento contrário ao uso da língua polonesa pela família acontece na narrativa de JOÃO:

Meu avô não quis que meu pai aprendesse a língua polonesa - sempre falava que na época de Getúlio Vargas era proibido falar línguas estrangeiras e que era para ele não aprender, que ele era brasileiro e aqui se fala o português - JOÃO.

A imposição da língua/identidade acontece devido ao receio provocado pelas proibições em relação às línguas imigrantes na Era Vargas - 1930 à 1945 (CAMPOS, 1998), quando se buscou, através de leis do governo federal, "silenciar" vozes de imigrantes que representavam algum "perigo" (sob o ponto de vista dos governantes da época) para a "hegemonia linguística" e para o poder público. Também havia o fato de que 
pouco entender a língua nacional/portuguesa prejudicava a comunicação com brasileiros e dificultava (principalmente) a venda de produtos de agricultura de subsistência, isso fez com que muitas famílias, que possuíam filhos em idade escolar que frequentavam escolas nas quais era aprendida a língua portuguesa, deixassem de lado a prática da língua materna junto aos seus descendentes.

\begin{abstract}
A língua polonesa é presente quando vou para a casa de meus pais; meu pai fala polonês e alguns parentes também. Falam o polonês entre a família; o português é usado normalmente no cotidiano. - JOANA

No começo [está se referindo à época em que entrou para a universidade], algumas pessoas caçoavam do jeito que eu falo algumas palavras [notamos que a pronúncia do "R" é feita como "tepe"], mas eu não ligo pra isso. - JOANA
\end{abstract}

Blommaert (2013) indica que a língua é um dos índices que imediatamente marca a diversidade; pequenas diferenças de sotaques nos dão pistas de diversidades regionais, de classe, etnia, gênero, etc. Através dos pais que moram (geralmente) em comunidades no interior, são agricultores e praticantes da língua materna, a identidade polonesa se faz presente. No caso de JOANA, no ambiente universitário, mais especificamente, em sua sala de aula, na qual a presença de descendentes de poloneses é mínima, não é exercida a identidade polonesa, que lhe traz lembranças de algumas situações embaraçosas (“caçoavam do jeito que eu falo..."), embora ela afirme o contrário (“eu não ligo pra isso"). Notamos a presença de alternância de códigos linguísticos: quando está com os pais, utiliza-se da língua polonesa; quando não está, utiliza-se unicamente da língua portuguesa, bem como a alternância de identidades polono-brasileira. Lembramos que a alternância de códigos linguísticos, segundo Pavlenko; Blackledge (2004, p. 10), muitas vezes, está ligada à competência linguística dos falantes. 


\section{CONSIDERAÇÕES FINAIS}

Como a cultura está presente nas relações dialógicas a partir dos atos de linguagem (BAKHTIN, 2010) e os seres humanos encontram-se em constantes atos de se reconstruir e se reinventar (BHABHA, 2014) e esses atos ocasionam (re)construções de suas culturas e identidades (HALL, 2009, p. 38), tanto as identidades, quanto as culturas estão sempre "em processo". A língua polonesa que ora aparece em "code-switching" (alternância de códigos linguísticos), ora somente como deixada de lado em detrimento da língua portuguesa, muitas das vezes, ocasionada pela reconstrução de identidades que propiciam as mudanças em atos reconstrutórios, moldados pelos papéis e tarefas desempenhados, permitem "uma certa continuidade das culturas de origem dos imigrantes, não sem transformações, devidas ao novo ambiente social" (CUCHE, 1999, p. 66), pois o ato de "deixar de lado" a primeira língua, por si só, já caracteriza uma mudança/negociação.

Sobre a influência da escola no abandono da língua materna (no caso, a polonesa) em detrimento da língua nacional, Makoni e Meinhof (2006, p. 193) posicionam-se que "línguas são produtos de intervenções sociais e históricas"; governos e instituições educacionais/escolares elegem uma variedade como padrão e representativa "apagando ou ignorando os modos como as pessoas vivem/constroem suas vidas sociais por meio da linguagem nas práticas linguísticas em que estão situadas" (MOITA LOPES, 2013, p. 106). A "padronização da língua" para promover o "processo de subordinação linguística" é construída partindo dos interesses políticos e econômicos (KROSKRITY, 2004, p. 502) e é justificada por instituições dominantes com o intuito de valorizar a língua padrão/nacional e, consequentemente, desvalorizar as variantes não-padrão e as formas intermediárias construídas pelos imigrantes e, dessa forma, por analogia, desvalorizar as formas culturais e identitárias associadas a elas.

Pavlenko (2004, p. 57-58), em sua pesquisa, verificou que houve participação ativa de organizações filantrópicas para auxiliar os imigrantes europeus em suas "americanizações"; nós verificamos que a situação de assimilação dos imigrantes poloneses no Brasil/no Paraná encontrou percalços: as comunidades situadas no interior em função da agricultura de subsistência (principal fonte de renda dos imigrantes e seus descendentes); a construção de escolas pelos próprios imigrantes; o fato de muitos "professores" dessas escolas serem os próprios imigrantes, segundo Wachowicz (1970, p. 20), pois, o governo brasileiro à época já encontrava dificuldades para suprir as escolas brasileiras com o número necessário de professores e não era diferente com relação às escolas construídas pelos imigrantes - além da falta de mão de obra qualificada, havia 
também a dificuldade no entendimento da língua polonesa por parte de professores brasileiros.

Em 1937, de acordo com Wachowicz (1970, p. 63), das "167 escolas polonesas no Paraná, 128 estavam em funcionamento, 31 fechadas por falta de professores e 8 escolas em construção". Quanto ao uso da língua polonesa "10 escolas utilizavam-se exclusivamente da língua polonesa, enquanto que 14 exclusivamente da portuguesa, ao passo que 143 escolas eram bilíngües". As escolas da imigração apresentavam às crianças que as frequentavam "2 pátrias", a pátria polonesa que "paulatinamente ia-se apagando em sua memória" (WACHOWICZ, 1970, p. 91) e a pátria brasileira, que as acolheu.

Para Silva (2009, p. 85), no caso das identidades nacionais, a língua é um dos elementos centrais: "a história da imposição das nações modernas coincide, em grande parte, com a história da imposição de uma língua única e nacional" e a identidade, tal como a diferença "está sujeita a vetores de força, a relações de poder. Elas não são simplesmente definidas, elas são impostas" (SILVA, 2009, p. 81). No caso das nossas narrativas, essa imposição é mencionada, de forma contundente, na Era Vargas, através das leis da época (CAMPOS, 1998), ocasionando a postura de alguns pais não praticarem/ não ensinarem a língua polonesa aos seus filhos.

Em nosso corpus, em relação à negociação de uso das línguas polonesa e portuguesa, concluímos que: o uso da língua polonesa se faz presente, via de regra, quando os avós fazem parte ou convivem com a família dos acadêmicos pesquisados; alguns pais (dos acadêmicos) fazem uso da língua de seus ancestrais, os que o fazem, quase sempre, vivem no interior e/ou são agricultores. Os fatos que contribuíram para os sujeitos pesquisados "deixarem de lado" a língua polonesa, geralmente, foram a entrada para a escola (em casa era usada) e a passagem da infância (com a presença dos avós que a falavam) para a adolescência e a vida adulta e, consequentemente, a entrada para a vida laboral. 


\section{REFERÊNCIAS:}

BAKHTIN, Mikhail. Questões de literatura e estética: A teoria do romance. São Paulo: Hucitec, 2010.

BHABHA, Homi. O local da cultura. Tradução de Myriam Ávila, Eliana Lourenço de Lima Reis, Gláucia Renate Gonçalves. Belo Horizonte: Ed. UFMG, 2014.

BLOMMAERT, Jan. Language and the study of diversity. Working papers in urban languages \& literacies. Paper 113. Universiteit Gent, University at Albany, Tilburg University, King's College London, 2013.

BUCHMANN, E. T. A trajetória do sol: um estudo sobre a identidade do imigrante polonês no sul do Brasil. Curitiba: Fundação Cultural, 1995.

CAMPOS, Cynthia Machado. A política da língua na era Vargas: proibição do falar alemão e resistência no sul do Brasil. 347f. Tese (Doutorado em História) - Instituto de Filosofia e Ciências Humanas. Universidade Estadual de Campinas, Campinas-SP, 1998.

CANAGARAJAH, Suresh. Multilingual writers and the struggle for voice in academic discourse. In: PAVLENKO, Aneta; BLACKLEDGE, Adrian (Orgs). Negotiation of identities in multilingual contexts. UK, USA, Canada, Australia: Multilingual Matters Ltd./Cromwell Press Ltd., 2004.

CANCLINI, Néstor Garcia. Culturas híbridas: estratégias para entrar e sair da modernidade. Tradução de Ana Regina Lessa e Heloísa Pezza Cintrão. São Paulo: EDUSP, 2015.

CORACINI, Maria José Rodrigues Faria. Identidade e discurso. Campinas; Ed.UNICAMP, 2003.

CUCHE, Denys. A noção de cultura nas ciências sociais. Tradução de Viviane Ribeiro. Bauru: EDUSC, 1999.

GEORGAKOPOULOU, Alexandra. Between narrative analysis and narrative inquiry: the long story of small stories research. Working papers in urban language \& literacies. Paper 131. Universiteit Gent, University at Albany, Tilburg University, King's College London, 2014.

HALL, Stuart. A identidade cultural na pós-modernidade. Tradução de Tomaz Tadeu da Silva e Guacira Lopes Louro, 11 ${ }^{\mathrm{a}}$ ed. Rio de Janeiro: DP\&A, 2006.

HALL, Stuart. Quem precisa de identidade? In: SILVA, Tomaz Tadeu da (Org.). Identidade e diferença: A perspectiva dos estudos culturais. 9. ed. Petrópolis: Vozes, 2009. 
KROSKRITY, Paul. Language Ideology. In: DURANTI, Alessandro. Acompanion to linguistic anthropology. Malden-MA-USA: Blackwell Publishing, 2004.

MAKONI, Sinfree; MEINHOF, Ulrike. Linguística aplicada na África: Desconstruindo a noção de "língua". In: MOITA LOPES, Luiz Paulo (org.). Por uma linguística aplicada indisciplinar. São Paulo: Parábola, 2006.

MOITA LOPES, Luiz Paulo. Identidades fragmentadas: a construção discursiva de raça, gênero e sexualidade em sala de aula. Campinas: Mercado de Letras, 2002.

MOITA LOPES, Luiz Paulo. Como e por que teorizar o português: recurso comunicativo em sociedades porosas e em tempos híbridos de globalização cultural. In: MOITA LOPES, Luiz Paulo (Org.). O Português no século XXI: cenário geopolítico e sociolinguístico. São Paulo: Parábola, 2013.

PAVLENKO, Aneta. The making of an American: Negotiation at the turnof the twentieth century. In: PAVLENKO, Aneta; BLACKLEDGE, Adrian (Orgs.). Negotiation of identities in multilingual contexts. UK, USA, Canada, Australia: Multilingual Matters LTD/Cromwell Press Ltd., 2004.

PAVLENKO, Aneta; BLACKLEDGE, Adrian. Introduction: New theoretical approaches to the study of negotiation of identities in multilingual contexts. In: PAVLENKO, Aneta; BLACKLEDGE, Adrian (orgs.). Negotiation of identities in multilingual contexts. UK, USA, Canada, Australia: MultilingualMatters LTD/Cromwell Press Ltd., 2004.

RYBA, Bernardete. Acadêmicos descendentes de poloneses: Negociação de identidades em uma universidade pública estadual paranaense. $174 \mathrm{f}$. Tese (Doutorado em Letras) Setor de Ciências Humanas, Universidade Federal do Paraná, Curitiba, 2019.

SAUSSURE, Ferdinand de. Curso de Lingüistica Geral. São Paulo: Cultrix, 1995.

SCHERER, Amanda Eloina. A constituição de sentido nas fronteiras do eu: memória da língua e a língua da memória. Revista do Programa de PósGraduação em Letras - UFSM, n. 26, p. 119-130, jun. 2003. Disponível em: $<$ https://periodicos.ufsm.br/letras/article/view/11887/7314>. Acesso em 20 jul. 2019.

SILVA, Tomaz Tadeu da. A produção social da identidade e da diferença. In: SILVA, Tomaz Tadeu da (Org.). Identidade e diferença: A perspectiva dos estudos culturais. 9. ed. Petrópolis: Vozes, 2009.

WACHOWICZ, Ruy Christovam. As escolas da colonização no Brasil. In: Anais da Comunidade Brasileiro-Polonesa. v. II - Ano 1970. Curitiba: Superintendência das Comemorações do Centenário da Imigração Polonesa ao Paraná, 1970. 